\title{
Sub national variation and inequalities in under-five mortality in Kenya since 1965
}

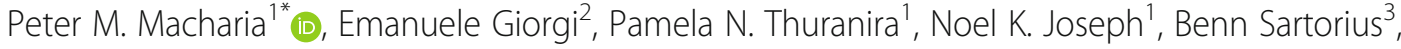
Robert W. Snow ${ }^{1,4}$ and Emelda A. Okiro ${ }^{1}$

\begin{abstract}
Background: Despite significant declines in under five mortality (U5M) over the last 3 decades, Kenya did not achieve Millennium Development Goal 4 (MDG 4) by 2015. To better understand trends and inequalities in child mortality, analysis of U5M variation at subnational decision making units is required. Here the comprehensive compilation and analysis of birth history data was used to understand spatio-temporal variation, inequalities and progress towards achieving the reductions targets of U5M between 1965 and 2013 and projected to 2015 at decentralized health planning units (counties) in Kenya.
\end{abstract}

Methods: Ten household surveys and three censuses with data on birth histories undertaken between 1989 and 2014 were assembled. The birth histories were allocated to the respective counties and demographic methods applied to estimate U5M per county by survey. To generate a single U5M estimate for year and county, a Bayesian spatio-temporal Gaussian process regression was fitted accounting for variation in sample size, surveys and demographic methods. Inequalities and the progress in meeting the goals set to reduce U5M were evaluated subnationally.

Results: Nationally, U5M reduced by $61.6 \%$, from 141.7 (121.6-164.0) in 1965 to 54.5 (44.6-65.5) in 2013. The declining U5M was uneven ranging between 19 and $80 \%$ across the counties with some years when rates increased. By 2000, 25 counties had achieved the World Summit for Children goals. However, as of 2015, no county had achieved MDG 4. There was a striking decline in the levels of inequality between counties over time, however, disparities persist. By 2013 there persists a 3.8 times difference between predicted U5M rates when comparing counties with the highest U5M rates against those with the lowest U5M rates.

Conclusion: Kenya has made huge progress in child survival since independence. However, U5M remains high and heterogeneous with substantial differences between counties. Better use of the current resources through focused allocation is required to achieve further reductions, reduce inequalities and increase the likelihood of achieving Sustainable Development Goal 3.2 on U5M by 2030.

Keywords: Under-five mortality, Sub national, Variation, Inequalities, Spatio-temporal, Kenya

\section{Background}

Under-five mortality (U5M), the probability that a child will die before reaching the age of five, is a benchmark of a country's health status and progress towards achievement of development goals [1,2]. Tracking U5M as part of international development targets began with the World Summit for Children in 1990, which set goals to

\footnotetext{
* Correspondence: pmacharia@kemri-wellcome.org

${ }^{1}$ Population Health Unit, Kenya Medical Research Institute-Wellcome Trust Research Programme, Nairobi, Kenya

Full list of author information is available at the end of the article
}

reduce U5M by a third and/or to 70 per 1000 live births between 1990 and 2000 [3]. This was followed by the Millennium Development Goal (MDG) 4 that proposed a reduction of U5M by two-thirds between 1990 and 2015 [4]. Currently, as part of the Sustainable Development Goals (SDGs), goal 3.2 seeks to end preventable deaths of children under- 5 years of age and to reduce U5M to 25 per 1000 live births by 2030 [5].

It has been estimated that there has been a $53 \%$ reduction in U5M globally between 1990 and 2015 [1, 6]. The slowest reductions in U5M were observed in

(c) The Author(s). 2019 Open Access This article is distributed under the terms of the Creative Commons Attribution 4.0 International License (http://creativecommons.org/licenses/by/4.0/), which permits unrestricted use, distribution, and reproduction in any medium, provided you give appropriate credit to the original author(s) and the source, provide a link to the Creative Commons license, and indicate if changes were made. The Creative Commons Public Domain Dedication waiver (http://creativecommons.org/publicdomain/zero/1.0/) applies to the data made available in this article, unless otherwise stated. 
sub-Saharan Africa (SSA). Only 11 countries out of 48 in SSA achieved the MDG 4 target by 2015 [6]. International benchmarking of national U5M developments goals has improved with time, with increasing data and improved methodologies. In recent years, new methodologies have been applied to understand within-country temporal and spatial heterogeneity in child survival [7]. However, examples of how U5M has changed at subnational levels remains limited to only a few SSA countries and imperfectly described [8-12]. In all countries, disease burdens are expected to be concentrated in a few sub-national areas; identification of these areas and directing suitable interventions to these areas will accelerate national child mortality reductions and ensure effective and equitable resource allocation.

Sub-national variations of child survival in Kenya were first described during the 1980s [13-16]. Advances in spatio-temporal statistics and analysis of multiple demographic datasets have provided new opportunities to study spatial and temporal heterogeneities of child survival across Kenya [1, 7, 17, 18]. However, recent analyses have not harnessed all the available sample surveys and census data, nor have they always provided annual predictions at sub-national units required for decentralized policy making since Kenya's independence. In addition, assessments of progress towards achieving global milestones and reducing inequalities in U5M at subnational units has not been attempted in Kenya.

Here the analysis of all available birth history data from household surveys and population census data is presented to provide annual predicted quantities of U5M since 1965 at each of Kenya's counties created in 2010 for decentralized health agenda. The estimated rates were used to express spatial and temporal heterogeneities in demographic transitions toward sub-national U5M goals and the long-term inequalities in child survival.

\section{Methods}

\section{Country context}

At the turn of the last century, the U5M rate was approximately 250 deaths per 1000 live births in Kenya [14]. Following the establishment of a rudimentary health system, U5M had declined to about 239 per 1000 live births by $1962[13,14]$. After independence in 1963, the government adopted socio-economic policies to alleviate hunger, ignorance and disease via the creation of equal opportunities for all citizens and an equitable distribution of wealth opportunities [19].

Twenty years after independence, Kenya began to launch policies to specifically improve child survival, notably in line with the Alma-Ata declaration in 1978 on primary health care. The Kenya expanded programme on immunization (EPI) was established in 1980 to coordinate immunization services for six childhood killer diseases, at the time including tuberculosis, polio, diphtheria, whooping cough, tetanus and measles [20]. However, during the late 1980s through to late 1990s, Kenya was affected by increasing prevalence of HIV [21], reintroductions of user fees in 1992 [22], poor coverage of basic healthcare services [23] and re-emerging malaria epidemics as a result of widespread resistance to Chloroquine [24].

At the beginning of 2000, there were numerous reproductive, maternal, newborn and child health $(\mathrm{RMNCH})$ policies aligning the health agenda with MDGs [23, 25]. Additional vaccines including Yellow fever, Hepatitis B and Haemophilus Influenza B type were added to the EPI bundle and user fees abolished in peripheral health facilities in 2004. Intensified efforts against malaria were mobilized under the Roll Back Malaria (RBM) initiative including replacing failing drugs with efficacious artemisinin-based combination (ACT) drugs and expanded, free delivery of insecticide-treated bed nets (ITNs) from 2006 [26, 27]. Free preventative interventions for HIV including preventing mother-to-child transmission and antiretroviral therapy were also expanded significantly from 2006 [21]. Pneumococcal conjugate vaccine was introduced in 2011 while rotavirus and measles second dose vaccines were introduced in 2014 and 2013 respectively. Since 2013, all services at government outpatient facilities and maternity services have been offered free of charge [22]. In addition, there has been renewed interests in expanding primary healthcare services as close to homesteads as possible through the Malezi Bora (good upbringing) initiative [28], the Beyond Zero [29] initiative and the universal health systems initiative focusing on $\mathrm{RMNCH}$ services among the underserved population [30].

2010 was a landmark year for Kenya when a new constitution was adopted which revised units of administration and health planning to 47 county governments (Fig. 1), including county ministries of health with broad policy directions maintained at the national level. The decentralized system came into effect in 2013 after the general elections and now represent units for federal policy planning to support the SDGs [31]. The counties cover variable climatic, ecological, socio-economic and infrastructure conditions. These dissimilarities govern the rainfall patterns, agricultural activities and human settlement with the highest population densities in the counties around Lake Victoria, central and the coastal areas while the southern and northern areas of Kenya are sparsely populated.

\section{Data assembly}

The ambition of U5M data assembly was to resolve all available data at sub-national resolutions (county) over 


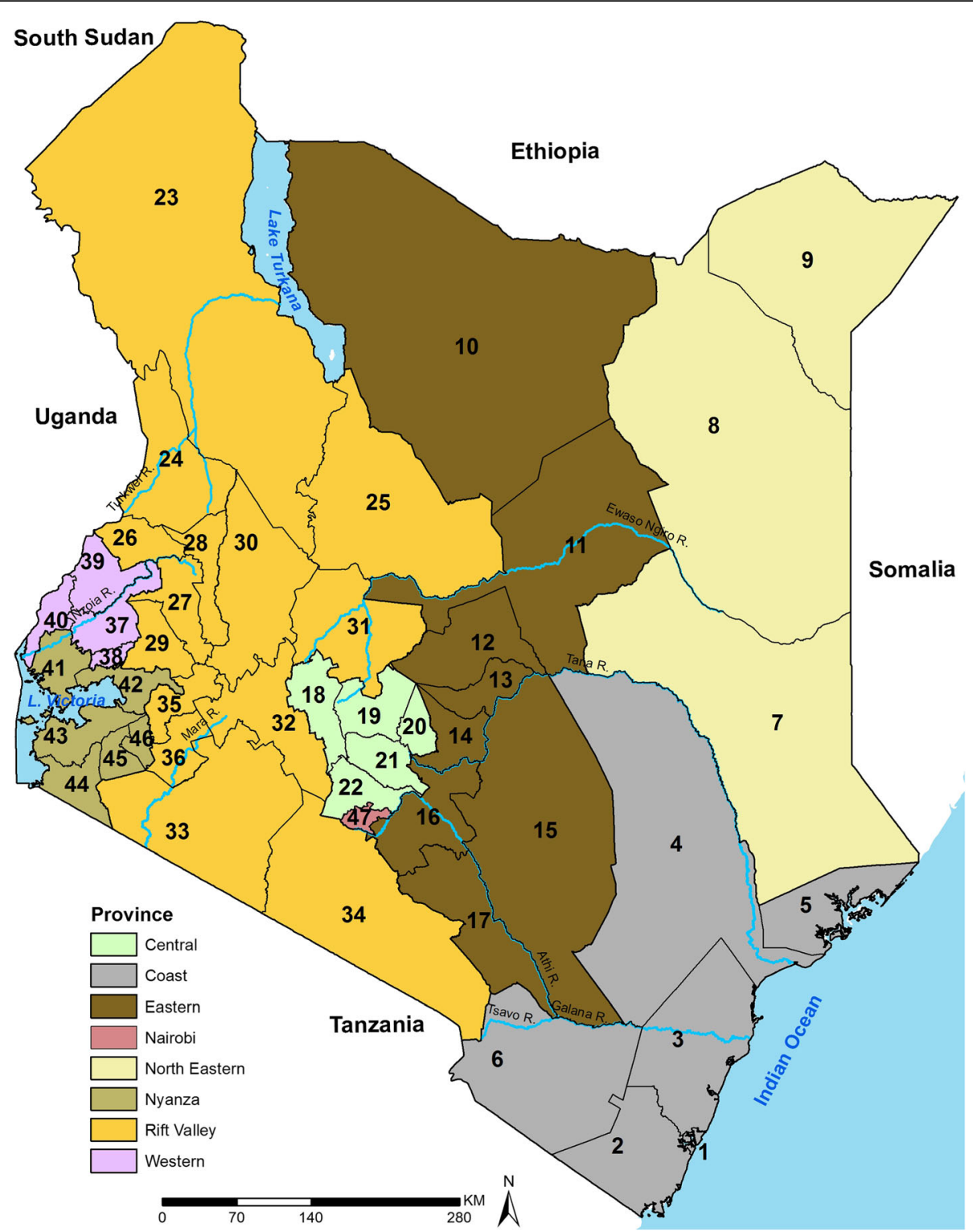

Fig. 1 Map of Kenya showing 8 provinces (colored) and the 47 sub-national units (counties) as dark lines water bodies and major rivers are shown in blue. Coast province: Mombasa [1], Kwale [2], Kilifi [3], Tana River [4], Lamu [5], Taita Taveta [6]; North Eastern province: Garissa [7], Wajir [8], Mandera [9]; Eastern province: Marsabit [10], Isiolo [11], Meru [12], Tharaka Nithi [13], Embu [14], Kitui [15], Machakos [16], Makueni [17]; Central province: Nyandarua [18], Nyeri [19], Kirinyaga [20], Murang'a [21], Kiambu [22]; Rift Valley province: Turkana [23], West Pokot [24], Samburu [25], Trans Nzoia [26], Uasin Gishu [27], Elgeyo Marakwet [28], Nandi [29], Baringo [30], Laikipia [31], Nakuru [32], Narok [33], Kajiado [34], Kericho [35], Bomet [36]; Western province: Kakamega [37], Vihiga [38], Bungoma [39], Busia [40]; Nyanza province: Siaya [41], Kisumu [42], Homa Bay [43], Migori [44], Kisii [45], Nyamira [46]; Nairobi province: Nairobi [47]

time. Sample household survey and population census data with either summary birth history (SBH) and/or complete birth history (CBH) collected between 1989 and 2014 in Kenya were assembled (Additional file 1). All the datasets were reconciled to the 47 counties boundaries (Fig. 1) as they were spatially misaligned over time (Additional file 2). The birth histories, maternal age, and/or time since first birth were collected through questions posed to women aged between 15 and 49 years. CBH records the date of each live birth and the date of death for those who had not survived while SBH records aggregated information on children ever born alive and who had since died [32]. Thirteen (13) national and/or sub-national datasets were available from the Kenya National Bureau of Statistics (KNBS) data archive [33], Integrated Public Use Microdata Series (IPUMS) [34], Multiple Indicator Cluster Survey (MICS) [35] and the Demographic and Health Survey (DHS) [36] data portal (Table 1). 
Table 1 Surveys and censuses undertaken in Kenya with data on either summary birth history (SBH) and/or complete birth history (CBH) since 1989 comprising of six Demographic and Health Surveys (DHS), four Multiple Indicator Cluster Surveys (MICS) and three population censuses. Table includes the number of counties covered, the sample size by source, and the exposure variable: whether maternal age (MA), and/or time since first birth (TFB) variables were collected

\begin{tabular}{|c|c|c|c|c|c|}
\hline Survey & Year of Survey & Counties with data & $\begin{array}{l}\text { Female } \\
\text { (15-49yrs) }\end{array}$ & Birth History & Exposure \\
\hline \multirow[t]{6}{*}{ Demography and Health Survey (DHS) } & 1989 & 38 & 7150 & $\mathrm{SBH}$ and $\mathrm{CBH}$ & MA and TFB \\
\hline & 1993 & 40 & 7540 & $\mathrm{SBH}$ and $\mathrm{CBH}$ & MA and TFB \\
\hline & 1998 & 38 & 7881 & $\mathrm{SBH}$ and $\mathrm{CBH}$ & $\mathrm{MA}$ and TFB \\
\hline & 2003 & 47 & 8195 & $\mathrm{SBH}$ and $\mathrm{CBH}$ & MA and TFB \\
\hline & 2008/09 & 47 & 8444 & $\mathrm{SBH}$ and $\mathrm{CBH}$ & MA and TFB \\
\hline & 2014 & 47 & 31,079 & $\mathrm{SBH}$ and $\mathrm{CBH}$ & MA and TFB \\
\hline \multirow[t]{4}{*}{ Multiple Indicator Cluster Survey (MICS) } & 2000 & 45 & 10,537 & $\mathrm{SBH}$ & MA and TFB \\
\hline & 2007 & 3 & 881 & $\mathrm{SBH}$ & MA and TFB \\
\hline & 2008 & 8 & 13,606 & $\mathrm{SBH}$ & MA only \\
\hline & 2011 & 6 & 5908 & $\mathrm{SBH}$ and $\mathrm{CBH}$ & $\mathrm{MA}$ and TFB \\
\hline \multirow[t]{3}{*}{ Population census } & $1989-5 \%$ & 47 & 238,027 & $\mathrm{SBH}$ & MA only \\
\hline & 1999-5\% & 47 & 345,647 & $\mathrm{SBH}$ & MA only \\
\hline & 2009-10\% & 47 & 934,904 & $\mathrm{SBH}$ & MA only \\
\hline
\end{tabular}

2009 MICS conducted in the informal settlements of Mombasa was excluded since U5M in urban areas was not represented while $2013 / 14$ MICS covering three counties was excluded due to under reporting of under- 5 deaths

\section{Under five mortality computation}

The household surveys and censuses data included various levels of information (Table 1). One direct and four independent indirect demographic methods were used to analyze $\mathrm{CBH}$ and $\mathrm{SBH}$ data respectively (Additional file 3). Using the direct method, the months a child lived before death or age five were allocated to six age-groups $[0-1,1-11,12-23,24-35,36-47,48-59$ months] and two-year time-periods. The monthly probability of survival $(P)$ was calculated as the ratio of deaths to the number of months lived in each group and period raised to a power equal to the number of months in the age-group. U5M for each period $\left({ }_{q} 5_{t}\right)$ was computed by subtracting from one the product of survival probabilities per period [32, 37] (Eq. 1) (Additional file 3). National trends were analyzed using the direct method since $\mathrm{CBH}$ does not require a life table model and the surveys are representative nationally.

$$
q 5_{t}=1-\left\{P_{t, m o .0^{*}}\left(P_{t, \text { mos. } 1-11}\right)^{11} *\left(P_{t, \mathrm{yr} 1}\right)^{12} *\left(P_{t, \mathrm{yr}} 2\right)^{12} *\left(P_{t, \mathrm{yr} 3}\right)^{12} *\left(P_{t, \mathrm{yr} 4}\right)^{12}\right\}
$$

The four indirect techniques included, two cohort and two period methods, indexed by either maternal age or time since first birth [32] adapted from Brass/ Trussell models converting the proportion of children dead (CD) to an U5M rate [38]. Using the cohort approach, women were grouped in 5-year cohorts of age or time since first birth, the $C D$ was computed per cohort and converted to U5M rate using eq. 2 . The regression coefficients $\left(\beta_{1 i}-\beta_{4 i}\right)$ and the country random effect (Uij) were generated from $\mathrm{CBH}$ obtained from household surveys across SSA [32] (Additional file 3).

$$
\begin{aligned}
\operatorname{logit}\left({ }_{5} q_{i j k}\right)= & \beta_{0 i}+U_{i j}+\beta_{1 i} \operatorname{logit}\left(\frac{C D_{i j k}}{C E B_{i j k}}\right) \\
& +\beta_{2 i} C E B_{i j k}+\beta_{3 i} \frac{P(15-19)_{j k}}{P(20-24)_{j k}} \\
& +\beta_{4 i} \frac{P(20-24)_{j k}}{P(25-29)_{j k}}+\varepsilon_{i j k}
\end{aligned}
$$

Where (j) indexes a country, (k) a survey, (i) a cohort, CD is children dead, CEB is Children Ever Born while (P) are parity ratios.

Limitations in the cohort approach were addressed through period techniques that account for U5M experiences of both young and older women when calculating U5M estimates for the most recent time and generating predictions for up to 25 years prior to a survey unlike cohort's 18 years [32]. Period methods generates children dead and children ever born for each year prior to the survey and converts it to a population level U5M (Eq. 3). The maternal age and time since first birth regional empirical distributions of births and deaths were used to redistribute reported births and deaths from each survey and census. The CD was computed and converted to an $\mathrm{U} 5 \mathrm{M}$ rate for years prior to the survey using 
regional empirical coefficients $\left(\beta^{0}{ }_{t}, U_{t j}\right.$ and $\left.\beta^{1}{ }_{t}\right)$ via eq. 3 [32] (Additional file 3).

$$
\begin{aligned}
\operatorname{Logit}\left(5 q 0_{i j k}\right)= & \beta^{0}{ }_{t}+U_{t j}+\beta^{1}{ }_{t} \log i t\left(\frac{C D_{t j k}}{C E B_{t j k}}\right) \\
& +\varepsilon_{i j k}
\end{aligned}
$$

Estimations were done in StataCorp. 2014 [Stata Statistical Software: Release 14. College Station, TX: StataCorp LP] by survey and county without pooling data to avoid over-smoothing of trends and allow detection of data quality issues on a case by case basis. Cohort methods allowed for the computation of U5M rates up to 18 years prior to a survey while period methods allowed for prediction of up to 25 years before the survey [32]. Due to the diversity of methods and data sources used, for each county for any single time point, there were multiple estimates of U5M requiring spatio-temporal modelling to smooth trends.

\section{Bayesian spatio-temporal modelling}

In order to borrow the strength of information in U5M estimates across time and space, while accounting for heterogeneity between surveys and the different techniques used for U5M estimation, a Bayesian spatiotemporal Gaussian process regression model [39, 40] with a heteroscedastic error component was developed (Eq. 4). Specifically, the latter was modelled as a Gaussian noise $\left(Z_{i j k t}\right)$ whose variance was the product of the log-transformed sample size from a given survey, county and year, and a second factor that accounts for the variability inherent to the demographic methods used to quantify U5M. The log of the sample size was used in order to obtain equally distributed weights to borrow information across all surveys and avoid excessive overweighting of the census data. The spatio-temporal correlation was specified using a separable structure, given by the product of a conditionally autoregressive structure in space and an autoregressive process of the first order in time (Additional file 3).

$$
\log \left\{\frac{Q_{i j k t}}{1-Q_{i j k t}}\right\}=\alpha+S_{k t}+Z_{i j k t}
$$

A Gaussian distribution was used for the logit-transformed U5M $\left(Q_{i j k t}\right)$ from the $i^{\text {th }}$ survey $(n=13)$, based on demographic method $j(n=5)$ for the $k^{\text {th }}$ county $(n=47)$ and year $t(n=49), 1965-2013 . S_{k t}$ is a spatio-temporal Gaussian process and $Z_{i j k t}$ is Gaussian noise.

The model was fitted using a bespoke Markov Chain Monte Carlo algorithm, developed in the $\mathrm{R}$ software environment (Version 3.4.1), that generated 10,000 predictive samples of smoothed U5M rates by county and year. To reduce the between-samples correlation, the algorithm was iterated for 110,000 times and retained every 10th sample after a burn-in of 10,000 samples. To assess the predictive performance of the model, a cross-validation procedure was used with a randomly selected hold-out sample containing $10 \%$ of the observed U5M rates for each possible combination of surveys and estimation methods. The root-meansquare-error and the bias were then used to summarize the accuracy and precision of the U5M model-based estimates.

The U5M posterior distribution was summarized by computing it's mean and $95 \%$ credible intervals (CI) for each year between 1965 and 2013. 2013 was the last year with reliable data to allow prediction of U5M [41]. Using the posterior mean, the annual rate of reduction (ARR) was estimated at national and county level between 2000 and 2013 by assuming an exponential function in the change between the two-time points [42] (Additional file 3 ). The progress of the 47 counties in meeting the targets set during the World Summit for Children [3] between 1990 and 2000 was then assessed. Achievement of the MDG 4 [4] by 2015 was evaluated using projections computed via 2000-2013 AAR assuming the trajectory remained constant. Finally, the inequality in U5M across the counties between 1965 and 2013 was calculated by adapting the Palma's inequality ratio [43] and computing the ratio as the average of U5M of $40 \%$ of the counties with the high U5M divided by the average U5M of $10 \%$ of counties with low U5M since 1965 . The results were mapped in ArcMap 10.5 (ESRI Inc., Redlands, CA, USA).

\section{Results}

The data assembled included ten sample household surveys and three population censuses carried out between 1989 and 2014 covering 460 county-years, 1.14 million households and 1.62 million women aged between 15 and 49 years (Table 1). The demographic methods and the spatio-temporal model allowed for 49 years of temporal predictions from 1965 to 2013 across all 47 counties. Overall, at the national level, there was a $61.6 \%$ reduction in the mean rate of U5M over 49 years from a rate of 141.7 (95\% CI: 121.6-164.0) deaths per 1000 live births in 1965 to 54.5 (44.6-65.5) per 1000 live births in 2013 (Fig. 2). There were two periods of substantial decline over the 49 years from the early 1970 s to late 1980 s and early 2000 to 2013 with U5M appearing to stagnate and/or reverse during the 1990s. The highest ARR (4.5\% [4.0-5.1]) was recorded between 2000 and 2013, 2.5 times faster relative to the rate of reduction in $1965-1988(1.8 \%$ [1.5-2.0]). At a national level, the goals set out in the World Summit for Children were not achieved by 2000 ; the estimated 


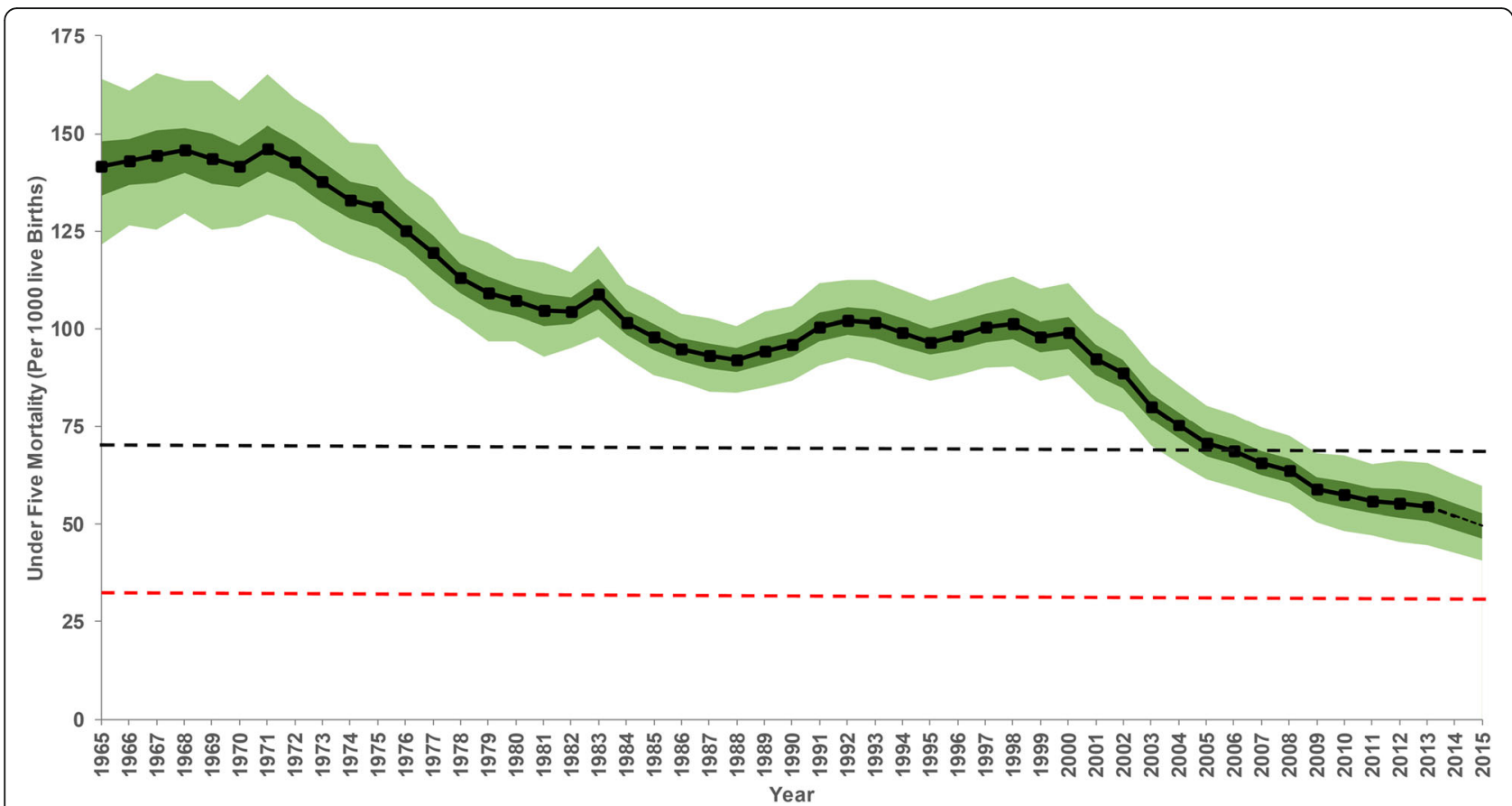

Fig. 2 The national annual mean (black line), 2.5-97.5\% (light green boundary) interquartile credibility range (ICR) and 25-75\% ICR (dark green boundary) of all cause-under five mortality per 1000 live births (U5M) in Kenya between 1965 to 2015 computed using direct demographic methods. The 2014-2015 U5M rates were computed using the average annual rate of reduction between 2000 and 2013 and shown as a dotted line. The U5M reduction target for World Summit for Children by 2000 is shown by a black dotted horizontal line while the red indicates the Millennium Development Goal 4 target. The graphs of county specific mean U5M and the corresponding 2.5-97.5\% ICR are presented in the appendix (Additional file 5)

U5M rate in 2000 was 99.3 (95\% CI: 88.3-111.7) per 1000 live births against a target of 70 deaths per 1000 live births. The overall change between 1990 and 2000 was a $3.3 \%$ (Fig. 2) reduction, far short of the $33.3 \%$ target. Additionally, using the 2015 projected U5M rates, the two-thirds (66.67\%) reduction target set as part of MDG 4 was not achieved nationally despite an overall reduction of 48.3\% (43.6-53.1) between 1990 and 2015 (Fig. 2).

These national estimates mask important sub-national differences in U5M rates over time (Fig. 3). Historically the highest mortality rates are those in the coastal areas, the arid and semi-arid areas around Lake Turkana and those around the Lake Victoria region (Fig. 3 and Fig. 4). The mean mortality rates in 1965 ranged from over 200 per 1000 live births in 11 counties to between 50 and 75 per 1000 live births in four counties. Overall, using 1965 as a baseline, by 2013, 23 counties had $\geq 60 \%$ decline in U5M rates, while a further 14 counties reduced U5M rates by at least a half (Additional file 4). All the counties except Nyeri and Nairobi had an overall reduction greater than a third (Additional file 4). By 2013, high mortality counties relative to the national average, continued to persist around Lake Victoria and the Tana river.

While the country did not achieve any of the goals set to reduce mortality rates in children below five years, there are some counties that achieved some of the goals (Table 2). Those that had an U5M rate of less than 70 per 1000 live births by 2000 included 24 counties (Mandera, Marsabit, Meru, Embu, Machakos, Makueni, Nyandarua, Nyeri, Kirinyaga, Murang'a, Kiambu, West Pokot, Samburu, Trans Nzoia, Uasin Gishu, Elgeyo Marakwet, Baringo, Laikipia, Nakuru, Narok, Kajiado, Kericho and Bomet). However, only two counties (Isiolo and Elgeyo Marakwet) had at least a third reduction in U5M rates between 1990 and 2000. No county in Western and Coast provinces achieved these targets compared to all counties in Central province and Nairobi that attained the targets set during the World Summit for Children to reduce U5M rates to $\leq 70$ per 1000 live births by 2000 and/or a one-third reduction between 1990 and 2000 (Table 2).

No county achieved a two-thirds reduction in U5M rates between 1990 and 2015 (MDG 4) based on projections made to 2015, however, nine counties had reductions $\geq 50 \%$, 34 reduced by at least $25 \%$ while four counties had reductions $<25 \%$ (Table 2). Whilst the national and sub-national MDG 4 was not achieved by 2015, more than half (25) of the counties reduced U5M by at least a third, while 30 had U5M rates below 70 per 1000 live births by 2015 achieving goals set during the World Summit for Children in 1990. Despite the 


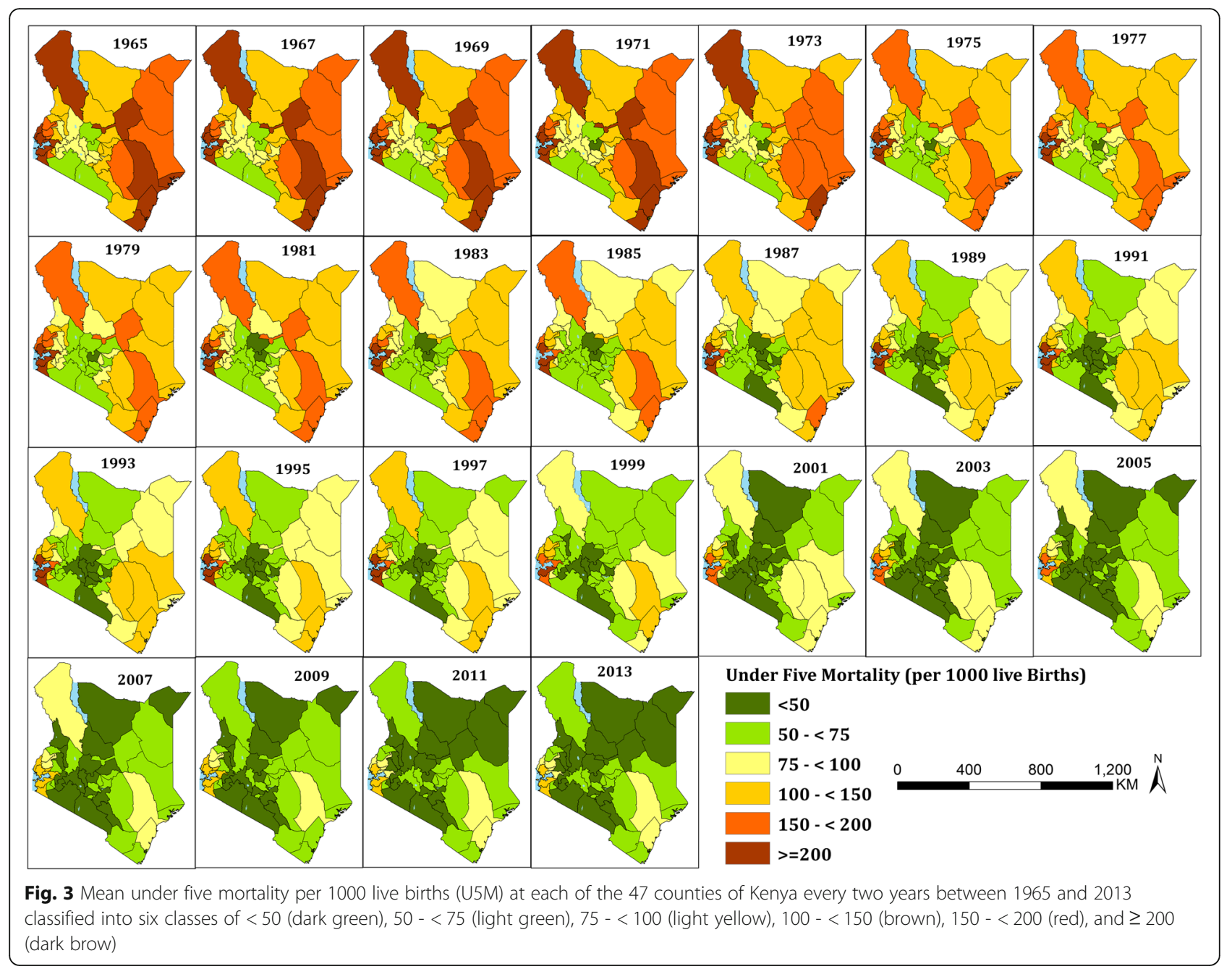

goals being achieved in only some of the counties, 2015 projections show mean mortality rates remain relatively low (<50 deaths per 1000 live births) in 21 counties (Nyeri, Kiambu, Trans Nzoia, Uasin Gishu, Wajir, Mandera, Marsabit, Isiolo, Machakos, Makueni, West Pokot, Samburu, Elgeyo Marakwet, Nandi, Baringo, Laikipia, Narok, Kajiado, Kericho, Bomet and Nyamira) (Table 2). Hence by 2015, no county had U5M rates of $\leq 25$ per 1000 live births, the target for 2030 (SDG 3.2).

However, there were some notable exceptions during the MDG period (1990-2015), where U5M rates increased relative to the 1990 rates. Counties in the Central province (Murang'a, Kiambu, Kirinyaga and Nyeri) and the adjacent areas (Laikipia, Nakuru, Embu, Nairobi) had small upsurges between 1990 and 1995. By 2010-2013, the reversal had spread outwards to other counties in Central province, Coast (Kilifi and Mombasa), Eastern (Machakos, Makueni, Tharaka Nithi and Meru) and the south part of Rift Valley Province (Narok and Kajiado). The overall percentage increase in these eight counties ranged from 5.3 in Nairobi to 32.7 per 1000 live births in Nyandarua county between 1990 and 2015 (Table 2). The Additional file 5 has detailed county profiles and the corresponding 95\% CIs graphs for each of the 47 counties.

On average, the gap between the highest and lowest recorded rates of U5M across Kenyan counties reduced by $58.6 \%$ (57.7-59.2), however, it was compounded by high magnitude of heterogeneity over time. By 2013 , the ratio between the highest and lowest U5M rates was 3.8 (3.74.1) from a ratio of $5.0(4.9-5 \cdot 2)$ in 1965 . The inequality index was high in the 1960s reduced marginally to 1970 s then increased and remained high in the mid-1980s to mid-1990s. From mid-1990, the inequalities have declined dramatically through to 2013 (Fig. 4). Values recorded in 2013 shows that high inequality continues to exist notably in Western and Nyanza Provinces (Fig. 4).

\section{Discussion}

In Kenya, shortly after independence, one in every seven Kenyan children born alive, died before the age of five, 49 years later, mortality has declined significantly, but 


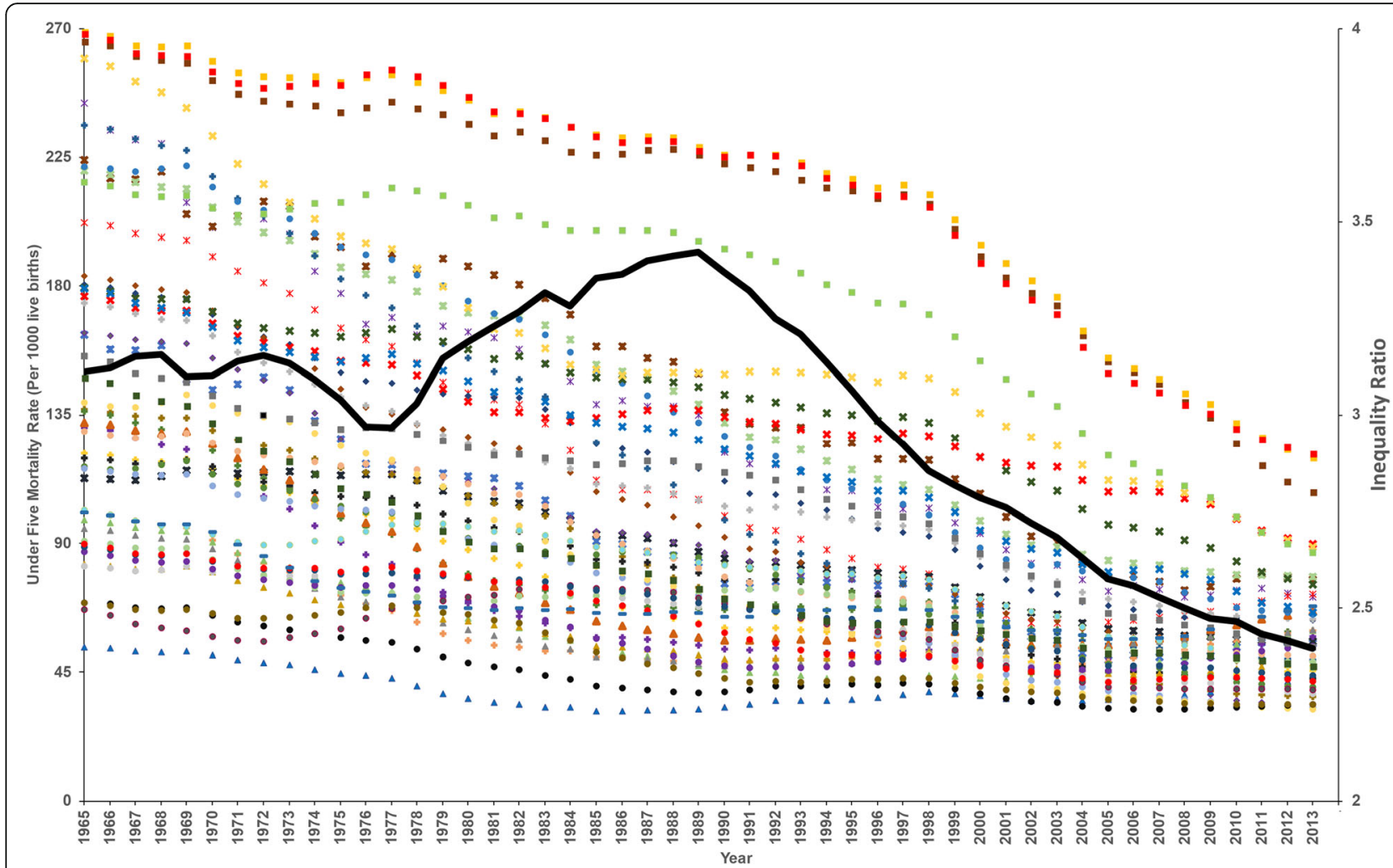

Fig. 4 A scatter plot showing changes in mean under five mortality per 1000 live births (U5M) per county between 1965 and 2013 . The provinces are differentiated by shapes; Coast $(*)$, North Eastern $(\bullet)$, Eastern $(+)$, Central $(\mathbf{\Delta})$, Rift valley $(\bullet)$, Western $(\mathbf{x})$, Nyanza $(\mathbf{\bullet})$ and Nairobi $(-)$ and counties with colors (indexed in Table 2). The bold dark line shows inequality ratio calculated by dividing U5M of 40\% of the counties with high U5M with the U5M of 10\% of counties with low U5M between 1965 and 2013

remains high, with one in every 19 children not reaching their fifth birthday (Fig. 2). The progress towards improving child survival has been uneven within Kenya's borders, with high rates of reduction in some areas and intractable slow progress in others (Fig. 3 and Fig. 4). Progress in meeting international goals aimed at reducing U5M has been less than optimal. Nationally, Kenya has not reached international goals set to reduce U5M rate by 2000 (World Summit for Children Goals) or 2015 (MDG 4) (Fig. 2), while only 25 counties met the 2000 goals, and none achieved the MDG 4 by 2015 (Table 2).

The declines in U5M started shortly after independence, through to 1988. Reductions coincide with efforts to establish policies to support economic growth, mitigate against high fertility rates and rapid population growth rates past independence in 1963 [44]. The stagnation of U5M rates and subsequent rise witnessed between 1988 and 2000 coincided with the increasing spread of the HIV epidemic and poverty [21, 45], low immunization coverage rates, poor quality of childcare [23], reintroduction of user fees [22], poor coverage of healthcare services, insufficient health workforce, a reduced focus on $\mathrm{RMNCH}[23,25]$ and resurgent malaria epidemics driven by El Niño rainfall anomalies and escalating drug resistance [24, 46]. From 2000 through to 2013, influential strategic changes to support health financing and access to healthcare, more vaccines and other preventive measures, effective medicines for malaria control and scaleup of interventions to control and manage HIV all led to a dramatic change in effective health service access [21-27].

Understanding the relative contributions of the broad health sector changes to sub-national U5M reductions is difficult, however, what is clear is that the U5M transitions have not been equal between counties and over time. The counties with the highest levels of U5M in 1965-1970 experienced the greatest reductions while those with lower starting levels had smaller changes observed over the 49-year period. Children born in Homa Bay county were 5 times as likely to die before age 5 as children born in Nyeri county in 1965 and reduced to 3.8 times by 2013 . The Western part of the country was the worst place to be born and remained the most disadvantaged through to 2013. These are areas characterized by high HIV prevalence [21] and intense malaria transmission [46]. Conversely high U5M in Northern part of the country, especially Turkana county, could be explained by 
Table 2 Progress of the 47 counties in meeting global under five mortality (U5M) reduction targets set during the World Summit for Children and the Millennium Development Goal 4 including the 2000, 2013 and 2015 projections U5M rates in Kenya

\begin{tabular}{|c|c|c|c|c|c|c|}
\hline $\begin{array}{l}\text { Province } \\
\text { name } \\
\text { [ Identifier } \\
\text { in Figure } \\
4 \text { ] }\end{array}$ & $\begin{array}{l}\text { County Name [unique } \\
\text { identifier used in Figure } \\
1 \text { and symbol used in } \\
\text { Figure 4] }\end{array}$ & $\begin{array}{l}\text { World Summit for Children: } \\
\text { reduce U5M rate to } 70 \\
\text { deaths per } 1000 \text { live births } \\
\text { by } 2000\end{array}$ & $\begin{array}{c}\text { World Summit for } \\
\text { Children: reduce } \\
\text { U5M by a third } \\
\text { between } 1990 \text { and } \\
2000\end{array}$ & $\begin{array}{l}\text { Estimated U5M in } \\
2013\end{array}$ & $\begin{array}{l}\text { Projected U5M in } \\
2015\end{array}$ & $\begin{array}{l}\text { Millennium } \\
\text { Development Goal } \\
\text { 4. Reduce U5M by } \\
\text { two-thirds between } \\
1990 \text { and } 2015\end{array}$ \\
\hline \multirow{6}{*}{$\begin{array}{c}\text { Coast } \\
{[*]}\end{array}$} & Mombasa $[1, *]$ & $67 \cdot 9[59 \cdot 3-77 \cdot 2]$ & $-10 \cdot 4[8 \cdot 8-12 \cdot 3]$ & $54 \cdot 9[43 \cdot 6-68 \cdot 1]$ & $54 \cdot 2[43 \cdot 0-67 \cdot 1]$ & $-28 \cdot 5[20 \cdot 6-36 \cdot 3]$ \\
\hline & Kwale $[2, *]$ & $93 \cdot 3[81 \cdot 6-106 \cdot 4]$ & $-23 \cdot 3[21 \cdot 5-24 \cdot 9]$ & $71 \cdot 1[56 \cdot 5-88 \cdot 2]$ & $69 \cdot 8[55 \cdot 4-86 \cdot 6]$ & $-42 \cdot 6[36 \cdot 0-48 \cdot 9]$ \\
\hline & Kilifi $[3, *]$ & $107 \cdot 0[94-1-121 \cdot 5]$ & $-21 \cdot 3[19 \cdot 4-22 \cdot 9]$ & $77 \cdot 2[61 \cdot 7-95 \cdot 2]$ & $75 \cdot 6[60 \cdot 4-93 \cdot 2]$ & $-44 \cdot 4[38 \cdot 1-50 \cdot 5]$ \\
\hline & Tana River $[4, \cdots]$ & $97 \cdot 6[88 \cdot 6-107 \cdot 2]$ & $-26 \cdot 3[25 \cdot 4-27 \cdot 0]$ & $78 \cdot 0[65 \cdot 8-91 \cdot 5]$ & $76 \cdot 8[64 \cdot 8-90 \cdot 2]$ & $-41 \cdot 9[37 \cdot 2-46 \cdot 5]$ \\
\hline & Lamu $[5, *]$ & $68 \cdot 8[60 \cdot 2-78 \cdot 2]$ & $-30 \cdot 8[29 \cdot 7-32 \cdot 0]$ & $72 \cdot 1[57 \cdot 5-89 \cdot 2]$ & $72 \cdot 4[57 \cdot 7-89 \cdot 5]$ & $-27 \cdot 2[19 \cdot 5-34 \cdot 8]$ \\
\hline & Taita Taveta $[6, *]$ & $71 \cdot 1[64 \cdot 2-78 \cdot 3]$ & $-15 \cdot 9[14 \cdot 9-17 \cdot 1]$ & $55 \cdot 4[46 \cdot 2-65 \cdot 7]$ & $54 \cdot 4[45 \cdot 4-64 \cdot 6]$ & $-35 \cdot 5[29 \cdot 7-41 \cdot 3]$ \\
\hline \multirow{3}{*}{$\begin{array}{c}\text { North } \\
\text { Eastern } \\
{[\bullet]}\end{array}$} & Garissa $[7,4]$ & $82 \cdot 0[74 \cdot 2-90 \cdot 1]$ & $-26 \cdot 6[26 \cdot 0-27 \cdot 3]$ & $63 \cdot 0[52 \cdot 8-74 \cdot 7]$ & $61 \cdot 9[51 \cdot 8-73 \cdot 4]$ & $-44 \cdot 5[39 \cdot 6-49 \cdot 2]$ \\
\hline & Wajir $[8,4]$ & $68 \cdot 3[61 \cdot 8-74 \cdot 9]$ & $-25 \cdot 9[25 \cdot 5-26 \cdot 4]$ & $46 \cdot 6[38 \cdot 9-55 \cdot 4]$ & $45 \cdot 5[37 \cdot 9-54 \cdot 0]$ & $-50 \cdot 6[46 \cdot 3-54 \cdot 8]$ \\
\hline & Mandera $[9,4]$ & $58 \cdot 6[51 \cdot 3-66 \cdot 5]$ & $-32 \cdot 4[31 \cdot 9-32 \cdot 9]$ & $32 \cdot 7[25 \cdot 3-41 \cdot 5]$ & $31 \cdot 4[24 \cdot 3-39 \cdot 9]$ & $-63 \cdot 7[59 \cdot 1-68 \cdot 2]$ \\
\hline \multirow{8}{*}{$\begin{array}{c}\text { Eastern } \\
{[+]}\end{array}$} & Marsabit $[10,+]$ & $48 \cdot 8[43 \cdot 9-54 \cdot 0]$ & $-31 \cdot 0[30 \cdot 7-31 \cdot 4]$ & $36 \cdot 4[30 \cdot 3-43 \cdot 5]$ & $35 \cdot 7[29 \cdot 7-42 \cdot 6]$ & $-49 \cdot 4[45 \cdot 3-53 \cdot 5]$ \\
\hline & Isiolo $[11,+]$ & $65 \cdot 8[60 \cdot 3-71 \cdot 6]$ & $-33 \cdot 0[32 \cdot 7-33 \cdot 4]$ & $49 \cdot 0[42 \cdot 1-56 \cdot 7]$ & $48 \cdot 0[41 \cdot 2-55 \cdot 6]$ & $-51 \cdot 1[47 \cdot 7-54 \cdot 4]$ \\
\hline & Meru $[12,+]$ & $48 \cdot 8[44 \cdot 9-52 \cdot 9]$ & $-7 \cdot 9[7 \cdot 0-8 \cdot 6]$ & $57 \cdot 1[49 \cdot 5-65 \cdot 6]$ & $57 \cdot 7[50 \cdot 0-66 \cdot 3]$ & $9 \cdot 1[1 \cdot 8-16 \cdot 7]$ \\
\hline & Tharaka Nithi $[13,+]$ & $64 \cdot 8[59 \cdot 2-70 \cdot 8]$ & $-2 \cdot 8[1 \cdot 8-3 \cdot 9]$ & $59 \cdot 3[50 \cdot 4-69 \cdot 3]$ & $59 \cdot 0[50 \cdot 1-68 \cdot 9]$ & $-11 \cdot 5[4 \cdot 4-18 \cdot 4]$ \\
\hline & Embu $[14,+]$ & $48 \cdot 6[44 \cdot 5-52 \cdot 8]$ & $1 \cdot 3[0 \cdot 2-2 \cdot 0]$ & $59 \cdot 1[51 \cdot 0-68 \cdot 3]$ & $59 \cdot 9[51 \cdot 6-69 \cdot 2]$ & $25 \cdot 0[16 \cdot 4-33 \cdot 8]$ \\
\hline & Kitui $[15,+]$ & $85 \cdot 3[79 \cdot 0-91 \cdot 9]$ & $-16 \cdot 9[16 \cdot 1-17 \cdot 8]$ & $63 \cdot 4[55 \cdot 0-72 \cdot 5]$ & $62 \cdot 1[53 \cdot 9-71 \cdot 1]$ & $-39 \cdot 5[35 \cdot 1-43 \cdot 8]$ \\
\hline & Machakos $[16,+]$ & $52 \cdot 6[48 \cdot 6-56 \cdot 8]$ & $-12 \cdot 6[12 \cdot 1-13 \cdot 5]$ & $45 \cdot 5[39 \cdot 4-52 \cdot 3]$ & $45 \cdot 0[39 \cdot 0-51 \cdot 8]$ & $-25 \cdot 2[19 \cdot 8-30 \cdot 4]$ \\
\hline & Makueni $[17,+]$ & $57 \cdot 3[52 \cdot 2-62 \cdot 7]$ & $-25 \cdot 8[24 \cdot 9-27 \cdot 0]$ & $42 \cdot 6[36 \cdot 0-50 \cdot 1]$ & $41 \cdot 8[35 \cdot 2-49 \cdot 2]$ & $-45 \cdot 8[41 \cdot 1-50 \cdot 6]$ \\
\hline \multirow{5}{*}{$\begin{array}{c}\text { Central } \\
{[\mathbf{\Lambda}]}\end{array}$} & Nyandarua $[18, \Delta]$ & $42 \cdot 8[38 \cdot 9-46 \cdot 9]$ & $-6 \cdot 5[5 \cdot 5-7 \cdot 7]$ & $59 \cdot 3[50 \cdot 6-69 \cdot 3]$ & $60 \cdot 6[51 \cdot 7-70 \cdot 8]$ & $32 \cdot 7[22 \cdot 8-42 \cdot 7]$ \\
\hline & Nyeri $[19, \Delta]$ & $36 \cdot 6[33 \cdot 6-39 \cdot 9]$ & $-12 \cdot 2[11 \cdot 3-13 \cdot 3]$ & $42 \cdot 4[36 \cdot 5-48 \cdot 9]$ & $42 \cdot 9[36 \cdot 9-49 \cdot 4]$ & $31 \cdot 5[22 \cdot 2-40 \cdot 4]$ \\
\hline & Kirinyaga $[20, \Delta]$ & $57 \cdot 3[52 \cdot 3-62 \cdot 6]$ & $-2 \cdot 8[1 \cdot 6-3 \cdot 9]$ & $66 \cdot 0[56 \cdot 7-76 \cdot 6]$ & $66 \cdot 6[57 \cdot 2-77 \cdot 3]$ & $19 \cdot 6[11 \cdot 2-28 \cdot 5]$ \\
\hline & Murang'a $[21, \Delta]$ & $52 \cdot 4[48 \cdot 0-57 \cdot 2]$ & $-11.5[10 \cdot 6-12 \cdot 5]$ & $59 \cdot 6[51 \cdot 4-69 \cdot 0]$ & $60 \cdot 2[51 \cdot 8-69 \cdot 6]$ & $28 \cdot 1[19 \cdot 5-37 \cdot 2]$ \\
\hline & Kiambu $[22, \Delta]$ & $49 \cdot 0[44 \cdot 9-53 \cdot 4]$ & $-1 \cdot 3[0 \cdot 2-2 \cdot 3]$ & $48 \cdot 0[41 \cdot 3-55 \cdot 8]$ & $48 \cdot 0[41 \cdot 3-55 \cdot 7]$ & $-3 \cdot 2[-10 \cdot 5-4 \cdot 23]$ \\
\hline \multirow{14}{*}{$\begin{array}{c}\text { Rift } \\
\text { Valley } \\
{[\bullet \cdot]}\end{array}$} & Turkana $[23, \bullet]$ & $88 \cdot 2[80 \cdot 4-96 \cdot 8]$ & $-30 \cdot 7[30 \cdot 1-31 \cdot 0]$ & $65 \cdot 0[54 \cdot 6-76 \cdot 6]$ & $63 \cdot 7[53 \cdot 5-75 \cdot 0]$ & $-49 \cdot 9[45 \cdot 8-54 \cdot 07]$ \\
\hline & West Pokot $[24, \bullet]$ & $57-1[51 \cdot 5-63 \cdot 1]$ & $-31 \cdot 0[29 \cdot 9-32 \cdot 0]$ & $39 \cdot 5[33 \cdot 1-46 \cdot 9]$ & $38 \cdot 6[32 \cdot 3-45 \cdot 7]$ & $-53 \cdot 3[49 \cdot 2-57 \cdot 3]$ \\
\hline & Samburu $[25, \bullet]$ & $47 \cdot 0[42 \cdot 6-51 \cdot 8]$ & $-32 \cdot 4[32 \cdot 0-32 \cdot 7]$ & $32 \cdot 6[27 \cdot 4-38 \cdot 5]$ & $31 \cdot 8[26 \cdot 7-37 \cdot 6]$ & $-54 \cdot 2[50 \cdot 6-57 \cdot 8]$ \\
\hline & Trans Nzoia $[26, \circ]$ & $61 \cdot 7[56 \cdot 2-67 \cdot 6]$ & $-21 \cdot 2[20 \cdot 0-22 \cdot 2]$ & $50 \cdot 5[42 \cdot 9-59 \cdot 0]$ & $49 \cdot 8[42 \cdot 4-58 \cdot 2]$ & $-36 \cdot 2[31 \cdot 1-41 \cdot 3]$ \\
\hline & Uasin Gishu $[27,0]$ & $51-1[46 \cdot 8-55 \cdot 8]$ & $-24 \cdot 5[23 \cdot 6-25 \cdot 4]$ & $37 \cdot 4[32 \cdot 0-43 \cdot 5]$ & $36 \cdot 6[31 \cdot 3-42 \cdot 6]$ & $-45 \cdot 9[41 \cdot 6-50 \cdot 0]$ \\
\hline & Elgeyo Marakwet $[28, \circ]$ & $43 \cdot 3[39 \cdot 0-47 \cdot 9]$ & $-38 \cdot 9[38 \cdot 1-39 \cdot 8]$ & $32 \cdot 0[26 \cdot 6-38 \cdot 0]$ & $31 \cdot 3[26 \cdot 1-37 \cdot 2]$ & $-55 \cdot 7[51 \cdot 8-59 \cdot 7]$ \\
\hline & Nandi $[29, \bullet]$ & $70 \cdot 5[64 \cdot 3-76 \cdot 9]$ & $-14 \cdot 5[13 \cdot 6-15 \cdot 4]$ & $46 \cdot 3[39 \cdot 3-54-1]$ & $45 \cdot 0[38 \cdot 2-52 \cdot 6]$ & $-45 \cdot 3[40 \cdot 9-49 \cdot 7]$ \\
\hline & Baringo $[30, \cdot]$ & $61 \cdot 1[56 \cdot 0-66 \cdot 3]$ & $-16 \cdot 9[16 \cdot 2-18 \cdot 0]$ & $48 \cdot 3[41 \cdot 6-55 \cdot 7]$ & $47 \cdot 6[41 \cdot 0-54 \cdot 8]$ & $-35 \cdot 2[30 \cdot 6-39 \cdot 8]$ \\
\hline & Laikipia $[31, \bullet]$ & $37 \cdot 3[34 \cdot 1-40 \cdot 7]$ & $-1 \cdot 6[0 \cdot 8-2 \cdot 6]$ & $33 \cdot 6[28 \cdot 9-38 \cdot 7]$ & $33 \cdot 3[28 \cdot 7-38 \cdot 4]$ & $-12 \cdot 0[6 \cdot 2-18 \cdot 0]$ \\
\hline & Nakuru $[32, \bullet]$ & $47 \cdot 6[44 \cdot 0-51 \cdot 5]$ & $1 \cdot 1[0 \cdot 4-2 \cdot 1]$ & $54 \cdot 0[47 \cdot 0-61 \cdot 8]$ & $54 \cdot 4[47 \cdot 4-62 \cdot 3]$ & $15 \cdot 8[8 \cdot 4-23 \cdot 7]$ \\
\hline & Narok $[33, \bullet]$ & $49 \cdot 3[45 \cdot 0-53 \cdot 7]$ & $-28 \cdot 4[27 \cdot 7-29 \cdot 3]$ & $38 \cdot 7[33 \cdot 1-45 \cdot 0]$ & $38 \cdot 0[32 \cdot 5-44 \cdot 3]$ & $-44 \cdot 7[40 \cdot 4-48 \cdot 8]$ \\
\hline & Kajiado $[34, \bullet]$ & $39 \cdot 9[36 \cdot 5-43 \cdot 4]$ & $-6 \cdot 5[5 \cdot 6-7 \cdot 3]$ & $33 \cdot 6[28 \cdot 8-38 \cdot 8]$ & $33 \cdot 2[28 \cdot 5-38 \cdot 4]$ & $-21 \cdot 9[16 \cdot 4-27 \cdot 5]$ \\
\hline & Kericho $[35, \bullet]$ & $56 \cdot 1[51 \cdot 7-60 \cdot 9]$ & $-16 \cdot 9[16 \cdot 1-17 \cdot 8]$ & $43 \cdot 6[37 \cdot 7-50 \cdot 1]$ & $42 \cdot 9[37 \cdot 1-49 \cdot 2]$ & $-36 \cdot 5[32 \cdot 1-41 \cdot 0]$ \\
\hline & Bomet $[36, \bullet]$ & $47 \cdot 0[42 \cdot 8-51 \cdot 5]$ & $-19 \cdot 7[18 \cdot 9-20 \cdot 7]$ & $41 \cdot 8[35 \cdot 6-48 \cdot 7]$ & $41 \cdot 5[35 \cdot 4-48 \cdot 4]$ & $-29 \cdot 1[23 \cdot 8-34 \cdot 4]$ \\
\hline \multirow{4}{*}{$\begin{array}{l}\text { Western } \\
{[x]}\end{array}$} & Kakamega $[37, \mathrm{x}]$ & $119 \cdot 9[110 \cdot 8-129 \cdot 3]$ & $-15 \cdot 6[14 \cdot 8-16 \cdot 3]$ & $75 \cdot 3[65 \cdot 0-86 \cdot 6]$ & $73 \cdot 0[63 \cdot 0-84 \cdot 0]$ & $-48 \cdot 6[44 \cdot 7-52 \cdot 4]$ \\
\hline & Vihiga $[38, x]$ & $119 \cdot 9[109 \cdot 2-131 \cdot 1]$ & $-10 \cdot 7[9 \cdot 7-12 \cdot 1]$ & $89 \cdot 4[75 \cdot 4-104 \cdot 9]$ & $87 \cdot 7[73 \cdot 9-102 \cdot 9]$ & $-34 \cdot 6[29 \cdot 1-40 \cdot 4]$ \\
\hline & Bungoma $[39, x]$ & $94 \cdot 5[85 \cdot 7-104-1]$ & $-22 \cdot 9[21 \cdot 9-23 \cdot 9]$ & $65 \cdot 8[54 \cdot 9-77 \cdot 8]$ & $64 \cdot 2[53 \cdot 6-76 \cdot 0]$ & $-47 \cdot 6[43 \cdot 0-52 \cdot 4]$ \\
\hline & Busia $[40, x]$ & $135 \cdot 6[122 \cdot 8-148 \cdot 8]$ & $-9 \cdot 0[8 \cdot 1-10 \cdot 4]$ & $88 \cdot 6[74 \cdot 3-105 \cdot 1]$ & $86 \cdot 1[72 \cdot 2-102 \cdot 2]$ & $-42 \cdot 2[36 \cdot 9-47 \cdot 3]$ \\
\hline \multirow{6}{*}{$\begin{array}{c}\text { Nyanza } \\
{[\mathbf{- 1}]}\end{array}$} & Siaya $[41, \mathbf{m}]$ & $190 \cdot 3[176 \cdot 7-204 \cdot 6]$ & $-14 \cdot 5[13 \cdot 8-15 \cdot 4]$ & $107 \cdot 7[92 \cdot 9-123 \cdot 9]$ & $103 \cdot 6[89 \cdot 4-119 \cdot 2]$ & $-53 \cdot 4[49 \cdot 7-57 \cdot 1]$ \\
\hline & Kisumu $[42$, - ] & $153 \cdot 7[142 \cdot 1-166 \cdot 0]$ & $-20 \cdot 3[19 \cdot 4-21 \cdot 2]$ & $86 \cdot 6[74 \cdot 6-99 \cdot 7]$ & $83 \cdot 3[71 \cdot 8-95 \cdot 9]$ & $-56 \cdot 8[53 \cdot 4-60 \cdot 2]$ \\
\hline & Homa Bay $[43, \square]$ & $194 \cdot 6[181 \cdot 3-208 \cdot 4]$ & $-13 \cdot 8[13 \cdot 1-14 \cdot 6]$ & $119 \cdot 6[103 \cdot 9-136 \cdot 3]$ & $115 \cdot 8[100 \cdot 6-131 \cdot 9]$ & $-48 \cdot 7[45 \cdot 0-52 \cdot 6]$ \\
\hline & Migori $[44, \square]$ & $188 \cdot 0[172 \cdot 8-203 \cdot 5]$ & $-16 \cdot 5[15 \cdot 7-17 \cdot 5]$ & $121 \cdot 1[103 \cdot 1-140 \cdot 7]$ & $117 \cdot 6[100 \cdot 1-136 \cdot 6]$ & $-47 \cdot 7[43 \cdot 4-52 \cdot 2]$ \\
\hline & Kisii $[45$, 口] & $86 \cdot 4[79 \cdot 5-93 \cdot 9]$ & $-24 \cdot 5[23 \cdot 6-25 \cdot 2]$ & $53 \cdot 4[45 \cdot 6-61 \cdot 9]$ & $51 \cdot 7[44 \cdot 1-59 \cdot 9]$ & $-54 \cdot 8[51 \cdot 2-58 \cdot 4]$ \\
\hline & Nyamira $[46, \square]$ & $59 \cdot 3[54-3-64 \cdot 5]$ & $-15 \cdot 9[15 \cdot 2-16 \cdot 6]$ & $47 \cdot 0[40 \cdot 1-54 \cdot 6]$ & $46 \cdot 3[39 \cdot 5-53 \cdot 8]$ & $-34 \cdot 3[29 \cdot 2-39 \cdot 4]$ \\
\hline Nairobi [-] & Nairobi $[47,-]$ & $62 \cdot 3[56 \cdot 5-68 \cdot 4]$ & $-2 \cdot 5[1 \cdot 3-3 \cdot 5]$ & $67 \cdot 5[57 \cdot 0-79 \cdot 4]$ & $67 \cdot 9[57 \cdot 3-79 \cdot 8]$ & $6 \cdot 3[-2 \cdot 1-15 \cdot 3]$ \\
\hline
\end{tabular}

Counties that achieved the targets are shown in green, amber shows those that missed the target by a small margin (20\%), while red indicates counties that missed the target with a large margin. The numbers (Fig. 1) and colors (Fig. 4) indicate the counties while the shapes (Fig. 4) indicate the 8 provinces of Kenya

harsh arid conditions leading to food insecurity and malnutrition [47].

Child mortality related inequalities have been documented across different socio-economic groupings (e.g. disparities in wealth, education etc.) as well as across geographic units [48]. Here the focus was on spatio-temporal inequalities between counties from 1965 to 2013 (Fig. 4) because spatial inequality links health outcomes to characteristics of a place that poverty or urban/rural taxonomies cannot highlight [49]. The cross-county inequalities were wide spread from 1965 to early 1970s and coincided with a phase when the Kenyan government was fighting poverty, ignorance and disease [13]. While U5M was decreasing during the 1980s, the existing inequalities were exacerbated and coincided with increasing HIV prevalence and rampant poverty across the country [45]. Conversely, inequalities started to decline in the early 1990s and linked to huge reductions in the differences between counties with low and high U5M rates and were sustained through to 2013. However, differences recorded in 2013 are still unacceptable and focus on reducing U5M in these high burden areas will narrow the gap.

Mortality rates in some of the counties of Central province appear to have stalled, stagnated, or reversed in most recent periods especially after 2003 (Additional file 5). These counties had low starting U5M level in 1965, experienced the smallest overall decline and despite the marginal increases in the recent years, they still have lower U5M levels relative to counties in Western areas of Kenya. 
The lower U5M rates might be explained by fertile lands supporting agriculture, economic and political stability, low prevalence of HIV and malaria. It is plausible that the residual deaths in these counties are those that occur during the first month of life accounting for about $45 \%$ of all under five deaths [50]. The continued declines in the other parts of Kenya are likely due to the deaths that occur outside the first month of life, however, further analysis is needed to establish the drivers' behind the recent rises and or stagnation in Central Kenya.

Projections to 2015 were undertaken for each county (Table 2) using the 2000-2013 trajectory rates to track progress across the MDG period. However, no county achieved MDG 4, and given ambitious 2030 targets, additional targeted efforts are required. Projections to 2030 were not attempted due to concerns regarding long-term projections using insufficient data; the year for which the projections are made should lie closer to the actual year of the most recent data [51]. Finally, the heterogeneous patterns in U5M observed in time and space are likely to be ascribed to uneven distribution, access and utilization of interventions and resources. This requires further evaluations to better explain and quantify specific contributions of these differences to these observed trends.

\section{Conclusion}

In conclusion, substantial progress in reducing U5M over time was witnessed subnationally, especially since 2000 . However, the rates of progress were slow and unequal across counties and as a result, the progress towards achieving international child survival targets remains sub-optimal across counties and over time. Huge spatiotemporal inequalities continue to persist with substantial gaps between the best and worst performing counties. The estimates generated can be used as a baseline for long-term monitoring and tracking progress and to inform better and efficient allocation of the resources through policies and programs that allow for equitable progress within the decentralized health planning structure in Kenya.

\section{Additional files}

Additional file 1: Data sources and assembly. (DOCX $20 \mathrm{~kb}$ )

Additional file 2: Methods of mapping district boundaries to county equivalent. (DOCX $21 \mathrm{~kb}$ )

Additional file 3: Demographic and spatio-temporal methods for estimating subnational under five mortality. (DOCX $89 \mathrm{~kb}$ )

Additional file 4: Mean under five mortality rate every ten years and the corresponding change between 1965 and 2013 by county in Kenya. (DOCX $21 \mathrm{~kb}$ )

Additional file 5: Graphs of county level mean under five mortality and the corresponding 2.5-97.5\% interquartile credibility range in Kenya. (DOCX $1378 \mathrm{~kb})$

\section{Abbreviations}

CBH: Complete Birth History; CD: Proportion of Children Dead;

DHS: Demographic and Health Survey; MICS: Multiple Indicator Cluster

Survey; RMNCH: maternal, newborn, and child health indicators;

SBH: Summary Birth History; SSA: Sub-Saharan Africa

\section{Acknowledgements}

The authors thank Abdisalan Noor for comments on an earlier version of this manuscript.

\section{Funding}

Funding was provided to EAO as part of her Wellcome Trust Intermediate Fellowship (number 201866); PMM acknowledges support for his Ph.D under the IDeALs Project (number 107769); EG was supported by an MRC Strategic Skills Fellowship in Biostatistics (MR/M015297/1); RWS is funded by Wellcome Trust Principal Fellowship (number 103602) and is grateful to the UK's Department for International Development for their continued support to a project strengthening the Use of Data for Malaria Decision Making in Africa (DFID Programme Code 203155). PMM, PNT, NJK, EAO, and RWS

acknowledge the support of the Wellcome Trust to the Kenya Major Overseas Programme (number 203077). The funder of the study had no role in study design, data collection, data analysis, data interpretation, or writing of the report.

\section{Availability of data and materials}

The full database of sample household surveys and population census data that support the findings of this study are available open access from online data repositories available to registered users. Population census (http:// statistics.knbs.or.ke/nada/index.php/home and https://

international.ipums.org/international-action/variables/group) Demographic Health Surveys (http://dhsprogram.com/data/available-datasets.cfm) and Multiple Indicator Cluster Surveys (http://mics.unicef.org/surveys).

\section{Authors' contributions}

PMM undertook the data assembly, data checking, analysis and writing of the first draft of the manuscript. EG and BS provided support in spatio-temporal model development. PNT and NJK contributed to data assembly, data checking, interpretation, revision of the manuscript drafts and supported the data validation. BS, RWS and EAO provided scientific advice and support throughout the project. EAO and RWS conceived the project, provided overall management, interpretation of results and contributed to second drafts of the manuscript. All authors reviewed the final analysis, have access to the data and approved the final manuscript. All authors read and met ICMJE criteria for authorship.

\section{Ethics approval and consent to participate}

This study used secondary data only, all publicly available to registered users from online data repositories. No individual patient level data used in this publication.

\section{Consent for publication}

Not applicable. The manuscript does not contain any individual person's data.

\section{Competing interests}

The authors declare that they have no competing interests.

\section{Publisher's Note}

Springer Nature remains neutral with regard to jurisdictional claims in published maps and institutional affiliations.

\section{Author details}

${ }^{1}$ Population Health Unit, Kenya Medical Research Institute-Wellcome Trust Research Programme, Nairobi, Kenya. ${ }^{2}$ Lancaster Medical School, Lancaster University, Lancaster, UK. ${ }^{3}$ Public Health Medicine, School of Nursing and Public Health, University of KwaZulu-Natal, Durban, South Africa. ${ }^{4}$ Centre for Tropical Medicine and Global Health, Nuffield Department of Clinical Medicine, University of Oxford, Oxford, UK. 
Received: 25 October 2018 Accepted: 24 January 2019 Published online: 04 February 2019

\section{References}

1. Wang $H$, Coates MM, Coggeshall M, Dandona L, Fraser M, Fullman N, et al. Global, regional, national, and selected subnational levels of stillbirths, neonatal, infant, and under-5 mortality, 1980-2015: a systematic analysis for the Global Burden of Disease Study 2015. Lancet. 2016;388:1725-74.

2. Reidpath DD, Allotey P. Infant mortality rate as an indicator of population health. J Epidemiol Community Health. 2003;57:344-6.

3. UNICEF. World summit for children. Popul Dev Rev. 1990;16:798-801 https:// www.unicef.org/wsc/goals.htm. Accessed 23 Feb 2017.

4. United Nations. United Nations Millenium declaration. 2000. http://www.un. org/en/ga/search/view_doc.asp?symbol=A/RES/55/2. Accessed 11 Sep 2017.

5. United Nations. The sustainable development goals report. 2016. https:// www.un.org/sustainabledevelopment/sustainable-development-goals/. Accessed 1 Dec 2016.

6. UN IGME. Child mortality Report 2015. Levels \& Trends in Child Mortality. 2015. http://www.childmortality.org/. Accessed 15 Nov 2015.

7. Golding N, Burstein R, Longbottom J, Browne AJ, Fullman N, et al. Mapping under-5 and neonatal mortality in Africa, 2000-2015: a baseline analysis for the sustainable development goals. Lancet. 2017;390:2171-82.

8. Arku RE, Bennett JE, Castro MC, Agyeman-Duah K, Mintah SE, Ware JH, et al. Geographical inequalities and social and environmental risk factors for under-five mortality in Ghana in 2000 and 2010: Bayesian spatial analysis of census data. PLoS Med. 2016;13:e1002038.

9. Dwyer-Lindgren L, Squires ER, Teeple S, Ikilezi G, Allen Roberts D, Colombara DV, et al. Small area estimation of under-5 mortality in Bangladesh, Cameroon, Chad, Mozambique, Uganda, and Zambia using spatially misaligned data. Popul Health Metrics. 2018;16:1-15.

10. Dwyer-Lindgren L, Kakungu F, Hangoma P, Ng M, Wang H, Flaxman AD, et al. Estimation of district-level under-5 mortality in Zambia using birth history data, 1980-2010. Spat Spatiotemporal Epidemiol. 2014;11:89-107.

11. Mercer LD, Wakefield J, Pantazis A, Lutambi AM, Masanja H, Clark S. Space-time smoothing of complex survey data: small area estimation for child mortality. Ann Appl Stat. 2015;9:1889-905.

12. Wollum A, Burstein R, Fullman N, Dwyer-Lindgren L, Gakidou E. Benchmarking health system performance across states in Nigeria: a systematic analysis of levels and trends in key maternal and child health interventions and outcomes, 2000-2013. BMC Med. 2015;13:208. https://doi. org/10.1186/s12916-015-0438-9.

13. Anker $R$, Knowles JC. An empirical analysis of mortality differentials in Kenya at the macro and micro levels. Econ Dev Cult Change. 1980;29:165.

14. National Research Council. Population dynamics of Kenya. Washington: National Academies Press; 1993.

15. Blacker J, Mukiza-gapere J, Kibet M, Airey P, Werner L. Mortality differentials in Kenya: paper presented to the International Union for the Scientific Study of population seminar on mortality and Society in sub-Saharan Africa. Yaounde: IUSSP; 1987.

16. Kemei KM. Differential Mortality in kenya: University of Nairobi; 1981. http:// erepository.uonbi.ac.ke/bitstream/handle/11295/23523/Kibet_Differential Mortality In Kenya.pdf?sequence=3\&isAllowed=y

17. Burke M, Heft-Neal S, Bendavid E. Sources of variation in under-5 mortality across sub-Saharan Africa: a spatial analysis. Lancet Glob Heal. 2016;4:e936-45.

18. Wakefield J, Fuglstad G, Riebler A, Godwin J, Wilson K, Clark SJ. Estimating under five mortality in space and time in a developing world context. Stat Methods Med Res. 2018;0:1-21. https://doi.org/10.1177/0962280218767988.

19. Ewbank D, Henin R, Kekovole J. An integration of demographic and epidemiologic research on mortality in Kenya. In: Determinants of mortality change and differentials in developing countries: the five country case study project; 1986. p. 33-85. https://pdfs.semanticscholar.org/cd80/ 71e0f989fcea75d74091526115596f9b4aed.pdf.

20. Government of Kenya: Ministry of Health. National Policy Guidelines on Immunization in Kenya. 2013. https://www.medbox.org/kenya-national-policyguidelines-on-immunization-2013/download.pdf. Accessed 2 Feb 2018.

21. Lupia R, Chien SC. HIV and AIDS epidemic in Kenya: an overview. J Exp Clin Med. 2012:4:231-4

22. Barasa E, Nguhiu P, Mcintyre D. Measuring progress towards sustainable development goal 3.8 on universal health coverage in Kenya. BMJ GlobalHealth. 2018;3:e000904.
23. Keats EC, Ngugi A, Macharia W, Akseer N, Khaemba EN, Bhatti Z, et al. Progress and priorities for reproductive, maternal, newborn, and child health in Kenya: a countdown to 2015 country case study. Lancet Glob Heal. 2017;5:e782-95. https://doi.org/10.1016/S2214-109X(17)30246-2.

24. Snow RW, Sartorius B, Kyalo D, Maina J, Amratia P, Mundia CW, et al. The prevalence of plasmodium falciparum in sub-Saharan Africa since 1900. Nature. 2017;550:515-8.

25. Keats EC, Macharia W, Singh NS, Akseer N, Ravishankar N, Ngugi AK, et al. Accelerating Kenya's progress to 2030: understanding the determinants of under-five mortality from 1990 to 2015. BMJ Glob Heal. 2018;3:e000655. https://doi.org/10.1136/bmjgh-2017-000655.

26. Amin AA, Zurovac D, Kangwana BB, Greenfield J, Otieno DN, Akhwale WS, et al. The challenges of changing national malaria drug policy to artemisinin-based combinations in Kenya. Malar J. 2007;6:72.

27. Noor AM, Amin AA, Akhwale WS, Snow RW. Increasing coverage and decreasing inequity in insecticide-treated bed net use among rural Kenyan children. PLoS Med. 2007;4:e255.

28. Clohossey PC, Katcher HI, Mogonchi GO, Nyagoha N, Isidro MC, Kikechi E, et al. Coverage of vitamin a supplementation and deworming during Malez bora in Kenya. J Epidemiol Glob Health. 2014;4:169-76.

29. Beyond Zero. Beyond Zero Intiative. 2018. https://www.beyondzero.or.ke/ about-us/. Accessed 22 Feb 2018

30. Governmnet of Kenya:Ministry of Health. Transforming Health Systems for Universal Health Care Vulnerable and Marginalized Groups Planning Framework. 2016. http://www.health.go.ke/wp-content/uploads/2016/03/ Transforming-Health-Systems-for-Universal-Care-VMGF-Final-30-March-2016. pdf. Accessed 8 Feb 2018.

31. Government of Kenya: Ministry of health. Kenya Health Policy 2014-2030 2014 http://www.health.go.ke. Accessed 22 May 2017.

32. Rajaratnam JK, Tran LN, Lopez AD, Murray CJL. Measuring under-five mortality: validation of new low-cost methods. PLoS Med. 2010;7:e1000253.

33. KNBS. Kenya National Data Archive. 2016. http://statistics.knbs.or.ke/nada/ index.php/home. Accessed 21 Apr 2016.

34. Minnesota Population Center. Integrated Public Use Microdata Series, International: Version 6.5 [Kenya Census data]. 2016. https://international.ipums. org/international-action/variables/group?id=fert. Accessed 21 Apr 2016.

35. UNICEF. UNICEF MICS Surveys. 2016. http://mics.unicef.org/surveys. Accessed 21 Apr 2016.

36. ICF. The DHS Program:Available Datasets. 2016. http://dhsprogram.com/ data/available-datasets.cfm. Accessed 21 Apr 2016.

37. Dwyer-Lindgren L, Gakidou E, Flaxman A, Wang H. Error and bias in under-5 mortality estimates derived from birth histories with small sample sizes. Popul Health Metrics. 2013;11:1-17.

38. Brass W. Uses of census or survey data for the estimation of vital rates. In: African seminar on vital statistics. Addis Ababa: United Nations economic and social council; 1964. p. 1-27. http://repository.uneca.org/handle/10855/ 9560. Accessed 17 Feb 2017

39. Rajaratnam JK, Marcus JR, Flaxman AD, Wang H, Levin-Rector A, Dwyer L, et al. Neonatal, postneonatal, childhood, and under-5 mortality for 187 countries, 1970-2010: a systematic analysis of progress towards Millennium Development Goal 4. Lancet. 2010;375:1988-2008. https://doi.org/10.1016/ S0140-6736(10)60703-9.

40. Mehdipour P, Navidi I, Parsaeian M, Mohammadi Y, Lakeh MM, Darzi ER, et al. Application of Gaussian process regression (GPR) in estimating under-five mortality levels and trends in Iran 1990 - 2013, study protocol. Arch Iran Med. 2014;17:189.

41. Boerma T, Victora C, Abouzahr C. Monitoring country progress and achievements by making global predictions: is the tail wagging the dog? Lancet. 2018;392:607-9. https://doi.org/10.1016/S0140-6736(18)30586-5.

42. UNICEF. How to calculate Average Annual Rate of Reduction ( AARR) of Underweight Prevalance. 2007. https://data.unicef.org/wp-content/uploads/ 2015/12/Technical_Note_AARR_185.pdf. Accessed 25 Jul 2017.

43. Cobham A, Schlögl L, Sumner A. Inequality and the tails: the Palma proposition and ratio. Glob Policy. 2016;7:25-36.

44. Hill K, Bicego G, Mahy M. Childhood mortality in Kenya : an examination of trends and determinants in the late 1980s to mid 1990s. 2001. https://pdfs. semanticscholar.org/d3fe/b1ec6b3d7821823bcfa96c87bb8349f4666e.pdf. Accessed 20 Feb 2018

45. Garenne M, Gakusi E. Health transitions in sub-Saharan Africa: overview of mortality trends in children under 5 years old (1950-2000). Bull World Health Organ. 2006;84:470-8. 
46. Macharia PM, Giorgi E, Noor AM, Waqo E, Kiptui R, Okiro EA, et al. Spatio-temporal analysis of plasmodium falciparum prevalence to understand the past and chart the future of malaria control in Kenya. Malar J. 2018:17:340.

47. Frings $M$, Lakes $T$, Müller $D$, Khan MMH, Epprecht M, Kipruto S, et al. Modeling and mapping the burden of disease in Kenya. Sci Rep. 2018;8:1-9.

48. Quentin W, Abosede O, Aka J, Akweongo P, Dinard K, Ezeh A, et al. Inequalities in child mortality in ten major African cities. BMC Med. 2014;12:95. https://doi. org/10.1186/1741-7015-12-95.

49. Jankowska MM, Benza M, Weeks JR. Estimating spatial inequalities of urban child mortality. Demogr Res 2013;28 January:33-62.

50. Liu L, Oza S, Hogan D, Chu Y, Perin J, Zhu J, et al. Global, regional, and national causes of under-5 mortality in 2000-15: an updated systematic analysis with implications for the sustainable development goals. Lancet. 2016;388. https://doi.org/10.1016/50140-6736(16)31593-8.

51. Boerma T, Victora C, Abouzahr C. Monitoring country progress and achievements by making global predictions: is the tail wagging the dog? Lancet. 2018:607-9.

Ready to submit your research? Choose BMC and benefit from:

- fast, convenient online submission

- thorough peer review by experienced researchers in your field

- rapid publication on acceptance

- support for research data, including large and complex data types

- gold Open Access which fosters wider collaboration and increased citations

- maximum visibility for your research: over $100 \mathrm{M}$ website views per year

At $\mathrm{BMC}$, research is always in progress.

Learn more biomedcentral.com/submissions 